\title{
Clinical efficacy of computed tomography-guided iodine- 125 seed implantation therapy in patients with advanced spinal metastatic tumors
}

This article was published in the following Dove Press journal:

OncoTargets and Therapy

18 December 2015

Number of times this article has been viewed

\author{
Liyun Zhang ${ }^{1,2, *}$ \\ Jian $\mathrm{Lu}^{2, *}$ \\ Zhongmin Wang ${ }^{3}$ \\ Yingsheng Cheng ${ }^{4}$ \\ Gaojun Teng ${ }^{5}$ \\ Kemin Chen ${ }^{4}$ \\ 'Medical College of Soochow \\ University, Suzhou, ${ }^{2}$ Department of \\ Radiology, Shanghai Ruijin Hospital \\ Luwan Branch, ${ }^{3}$ Department of \\ Radiology, Shanghai Ruijin Hospital, \\ ${ }^{4}$ Department of Radiology, Shanghai \\ the Sixth People Hospital, Shanghai, \\ ${ }^{5}$ Department of Radiology, Jiangsu \\ Key Laboratory of Molecular and \\ Functional Imaging, Zhongda Hospital, \\ Medical School, Southeast University, \\ Nanjing, People's Republic of China \\ *These authors contributed equally \\ to this work
}

\begin{abstract}
Objective: The purpose of this study was to examine the safety and clinical efficacy of computed tomography (CT)-guided radioactive iodine-125 $\left({ }^{125} \mathrm{I}\right)$ seed implantation treatment in patients with spinal metastatic tumors.
\end{abstract}

Methods: We retrospectively analyzed 20 cases of spinal metastatic tumors, including nine men and eleven women aged 50-79 years (mean age: 61.1 years). We used treatment planning system (TPS) to construct three-dimensional images of the spinal metastatic tumors and to determine what number and dose rate distribution to use for the ${ }^{125} \mathrm{I}$ seeds. The matched peripheral dose of the ${ }^{125} \mathrm{I}$ seed implantation was 90-130 Gy. Twenty-four spinal metastatic tumors were treated by CT-guided radioactive ${ }^{125}$ I seed implantation. A median of 19 (range: 4-43) ${ }^{125}$ I seeds were implanted.

Results: Twenty cases were followed for a median of 15.3 months (range: $7-32$ months). The rate of pain relief was $95 \%$. The median control time for all of the patients was 12.5 months. The 3-, 6-, and 12-month cumulative local control rates were $100 \%, 95 \%$, and $60 \%$, respectively. The median survival time for all of the patients was 16 months. The cumulative 6 - and 12 -month survival rates were $100 \%$ and $78.81 \%$, respectively. No major complications were observed. No ${ }^{125}$ I seeds were lost or migrated to other tissues or organs.

Conclusion: CT-guided radioactive ${ }^{125} \mathrm{I}$ seed implantation is a safe, effective, and minimally invasive method for the treatment of patients with spinal metastatic tumors. It is a possible alternative therapy for the treatment of spinal metastases.

Keywords: spinal metastatic tumor, iodine isotopes, computed tomography guided, interventional treatment

\section{Introduction}

The spine is a common location for metastases for many malignant tumors. ${ }^{1}$ A common symptom of spinal metastases is back pain, and it can severely affect patient's quality of life. The traditional treatment for spinal metastases is open surgery, which often causes considerable trauma, results in complications, and delays treatment of the primary disease because of prolonged hospitalization. ${ }^{2,3}$ With the development of interventional therapy, radioactive iodine-125 $\left({ }^{125} \mathrm{I}\right)$ seed implantation has been widely used in many primary and secondary malignant tumors and has achieved satisfactory clinical outcomes. ${ }^{4-7}$ Because the ${ }^{125}$ I seed has a long half-life and low energy, it destroys tumor cells persistently but is also relatively safe for surrounding normal tissues. ${ }^{8,9}$ The results of our previous studies showed that ${ }^{125} \mathrm{I}$ seed implantation can produce adequate pain relief for patients with unresectable pancreatic cancer and symptomatic retroperitoneal lymph node metastases. ${ }^{5,10}$ The aim of this study was to evaluate the feasibility of ${ }^{125}$ I seed implantation for the treatment of spinal metastases.
Correspondence: Zhongmin Wang Department of Radiology, Shanghai Ruijin Hospital, No 149 Chongqin North Road Shanghai 200020, People's Republic of

Email james0722@I63.com

Yingsheng Cheng

Department of Radiology, Shanghai the Sixth People Hospital, No 600 Yishan Road Shanghai 200233, People's Republic of China

Email cheng_y_sh@I26.com 


\section{Materials and methods}

\section{Patients}

Between May 2008 and October 2014, 20 consecutive patients with 24 spinal metastases were included in this prospective study. Nine of the patients were men and eleven were women, with ages ranging from 50 years to 79 years (median: 61.1 years). Among the patients, seven had lung cancer, three had hepatocarcinoma, three had rectal cancer, two had gastric cancer, two had renal carcinoma, one had thyroid cancer, one had breast cancer, and one had ovarian cancer. All of the primary tumors were confirmed by operation or puncture biopsy. Among the 24 vertebral lesions, eleven were located in thoracic vertebrae and 13 were located in lumbar vertebrae. Two patients had two lesions, and one patient had three lesions. The study protocol was approved by the Rujin Hospital, Luwan Branch ethics committee, and written informed consent was obtained from each patient.

\section{Instruments}

We used a Siemens computed tomography (CT) scanner with the following spinal imaging conditions: $120 \mathrm{kV}, 275 \mathrm{~mA}$, and a $5 \mathrm{~mm}$ width. The ${ }^{125} \mathrm{I}$-sealed seed sources were supplied by XinKe Pharmaceutical Ltd., Shanghai, People's Republic of China. Before the ${ }^{125}$ I seed brachytherapy, the Fudan TPS 2.00 brachytherapy planning system (Fudan University, Shanghai, People's Republic of China) was used to determine the number and position of the ${ }^{125}$ I seeds to implant by generating isodose curves of different percentages of predicted tumor regression and a dose-volume histogram based on the prescribed matched peripheral dose (MPD) of 90-130 Gy designed to encompass the planned target volume (PTV)., ${ }^{4,11}$ The PTV was a $0.5-1.5 \mathrm{~cm}$ expansion of the gross tumor volume. The PTV was covered by $90 \%$ of the isodose curves. The organ-at-risk (OAR) dose distribution was also calculated using TPS.

For the seed implantation, we used $18 \mathrm{G}$ implantation needles and a turntable implantation gun (XinKe Pharmaceutical Ltd.). The ${ }^{125}$ I seeds were manufactured from silver rods, which absorbed ${ }^{125} \mathrm{I}$, and were enclosed in a titanium capsule welded by a laser. The diameter of each seed was $0.8 \mathrm{~mm}$, the length of each seed was $4.5 \mathrm{~mm}$, and the thickness of the wall of the titanium capsule was $0.05 \mathrm{~mm} .{ }^{125} \mathrm{I}$ produces gamma rays $(5 \% 35 \mathrm{keV}$ and $95 \% 28 \mathrm{keV})$ with a half-life of 59.6 days, a half-value thickness of $0.025 \mathrm{~mm}$ of lead, a penetration of $17 \mathrm{~mm}$, an incipient rate of $7 \mathrm{cGy} / \mathrm{h}$, and activities of $0.5-0.8 \mathrm{mCi}$.

\section{Preoperative preparation}

The routine preoperative laboratory tests included routine blood tests of liver and kidney function, blood glucose, and coagulation function. The imaging data included X-ray, $\mathrm{CT}$, and/or magnetic resonance imaging (MRI) images of spinal lesions.

TPS was used to calculate the total volume of each tumor according to the preoperative CT image. ${ }^{12}$ Briefly, a threedimensional reconstruction model was generated based on CT or MRI images with the margin of the tumor precisely outlined to facilitate the calculation of the tumor MPD. The expected number of implanted seeds was calculated using the modified level formula. ${ }^{13}$

\section{CT-guided implantation protocol}

The patients were placed in the prone position. CT imaging was performed at $5 \mathrm{~mm}$ intervals. The puncture region was sterilized and locally anesthetized with $1 \%$ lidocaine. The puncture point position was determined on the basis of the title angle of the pedicle, the distance between the puncture point and the spinous process, and the depth from the skin to the pedicle, which were all determined by $\mathrm{CT}$ imaging. Then, $18 \mathrm{G}$ implantation needles were inserted with $\sim 1 \mathrm{~cm}$ distance between adjacent needles. The direction of the needle tip was adjusted constantly during the implantation process to achieve an ideal distribution of the ${ }^{125} \mathrm{I}$ particles. During the needle placement, care was taken to keep the needles at least $1 \mathrm{~cm}$ away from large blood vessels and the spine. All of the ${ }^{125}$ I seeds were placed at distances of $0.5-1.0 \mathrm{~cm}$ from one another. Then, the implantation puncture site was bandaged and compressed to achieve hemostasis.

\section{Postimplant dosimetry identification}

A CT scan was performed within 24 hours after seed implantation. CT images were input into TPS to allow a radiation therapist to assess the implant quality. The actual dose was evaluated according to the dose-volume histogram, and the OAR doses were assessed.

\section{Pain relief}

Numerical rating scale pain scores were recorded as $0-10$, with a score of 0 indicating no pain, scores of 1-3 indicating mild pain, scores of 4-6 indicating moderate pain, and scores of 7-10 indicating severe pain. Scoring that began after the ${ }^{125}$ I seeds was implanted.

\section{Evaluation of curative effect}

The efficacy of the treatment was determined according to the tumor response standards suggested by the World Health Organization. ${ }^{14}$ Briefly, complete response (CR) was defined as the complete disappearance of the lesion lasting 
for $>4$ weeks. Partial response (PR) was defined as a decrease in the size of the lesion (ie, the longest dimension multiplied by the maximal upright dimension) by $>50 \%$ lasting for 4 weeks. Stable disease (SD) was defined as a decrease in the size of the tumor of $<50 \%$ or an increase in the size of the tumor of $<25 \%$. Local tumor control after brachytherapy was defined as the absence of tumor progression on $\mathrm{CT}$ $(\mathrm{SD}+\mathrm{PR}+\mathrm{CR})$.

\section{Follow-up}

The intended follow-up period was 2 years, with visits at 1 month, 3 months, and every 3 months thereafter for postintervention clinical examinations, blood sampling, and CT and/or MRI examinations of the spine. Follow-up CT scans to evaluate the response were obtained for all of the patients at various intervals after implantation. To calculate survival, all deaths were scored as an event. The times of local control and survival were calculated from the date of seed implantation to the date of death or the last follow-up.

\section{Statistical analysis}

Using STATA 13.0 software (StataCorp LP, College Station, TX, USA), local control rates and survival rates were calculated by the Kaplan-Meier method.

\section{Results}

\section{Pain relief}

No patients were lost to follow-up. A median of 19 (range: 4-43) ${ }^{125}$ I seeds was implanted. Symptoms of refractory pain were significantly resolved after treatment $(P<0.05)$. The pain relief rate was $95 \%$. The changes in pain scores are shown in Table 1.

\section{Response to treatment}

Twenty cases (100\%) were followed, with a median follow-up time of 15.3 months (range: 7-32 months). The success rate of the puncture operations was $100 \%$. The average number of seeds implanted per patient was 19 (range: 4-43). The activity of the seeds ranged from $0.5 \mathrm{mCi}$ to $0.8 \mathrm{mCi}$, and the MPD was 90-130 Gy. The PTV edge was covered by $80 \%-90 \%$ of the isodose curves. The cord doses

Table I Pain release $(n=20)$

\begin{tabular}{lllll}
\hline & $\begin{array}{l}\text { No pain } \\
\text { (\%) }\end{array}$ & $\begin{array}{l}\text { Mild pain } \\
(\%)\end{array}$ & $\begin{array}{l}\text { Moderate } \\
\text { pain (\%) }\end{array}$ & $\begin{array}{l}\text { Severe } \\
\text { pain (\%) }\end{array}$ \\
\hline Preoperation & $0.0(0 / 20)$ & $5.0(1 / 20)$ & $20.0(4 / 20)$ & $75.0(15 / 20)$ \\
Postoperation & $25.0(5 / 20)$ & $45.0(9 / 20)$ & $25.0(5 / 20)$ & $5.0(1 / 20)$ \\
\hline Note: Data are presented as \% (cases). & &
\end{tabular}

were $\leq 30 \mathrm{~Gy}$, and the doses for the other OARs, such as the intestine and liver, were $<25 \mathrm{~Gy}$. CT imaging was performed every 3 months after treatment. Thirteen patients survived beyond 12 months of follow-up, and the longest survival time was 32 months. The soft masses around the vertebrae became smaller by differing degrees among 16 patients (Figure 1).

\section{Local control and survival time}

Because of poor health, many patients refused to undergo further therapy after seed implantation. Only four patients received chemotherapy, and they received two to six cycles of treatment. The median control time for all of the patients was 12.5 months (95\% confidence interval: 8-15.5 months). The 3-, 6-, and 12-month cumulative local control rates were $100 \%, 95 \%$, and 60\%, respectively (Figure 2). The median survival time for all of the patients was 16 months $(95 \%$ confidence interval: $13-27$ months). The cumulative 6- and 12-month survival rates were $100 \%$ and $78.81 \%$, respectively (Figure 3).

\section{Complications}

All of the operations were successfully performed. No mortality or morbidity was attributable to the ${ }^{125} \mathrm{I}$ seed implantation. No serious complications, such as fever, infection, or osteoradionecrosis, were observed during the follow-up period. No ${ }^{125}$ I seeds were lost or migrated to other tissues or organs. Six patients developed a hemorrhage at the puncture site, and the hemorrhage was stopped by local compression in all six cases.

\section{Discussion}

The spine is the most common site for bone metastases, and the incidence of spinal metastases is increasing. The most common primary carcinoma sites in patients with spinal metastases are the lungs, prostate, kidneys, breasts, and other organs. ${ }^{15-18}$ Choosing the right therapy for metastatic spinal tumors is often difficult and depends on many factors, including vertebral involvement, vertebral canal invasion, neurological status, life expectancy, general health status, and malignancy prognosis.

With improvements in chemotherapy, radiotherapy, and hormonal therapies, survival times have increased. Although surgery is now accepted as the preferred treatment for spinal metastases, the surgical complication rate can be as high as $20 \%-30 \%$, with the most common complication being wound infection. ${ }^{19-21}$ In some cases, surgery is not possible. Botelho et al performed a study to quantify the distribution of vertebral involvement in spinal metastases and to determine 


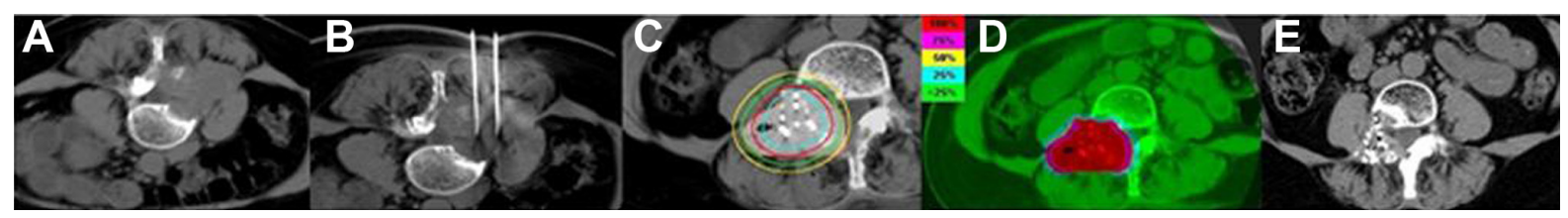

Figure I A 64-year-old female lung cancer patient with lumbar vertebral metastasis.

Notes: (A) CT localization before ${ }^{125}$ seed implantation. (B) The patient was in the prone position, percutaneous puncture was conducted under CT scan, and the puncture needles were placed in the tumor. (C) CT scan after ${ }^{125} \mathrm{I}$ seed implantation and isodose curves on TPS. The isodose lines shown are those for $160 \mathrm{~Gy}$ (bluish green), $100 \mathrm{~Gy}$ (red), $60 \mathrm{~Gy}$ (green), and $30 \mathrm{~Gy}$ (yellow). (D) Dose distributions of OAR on TPS after seed implantation based on CT scan, the colors range from inside (red) to outside (green) and show $100 \%, 75 \%, 50 \%, 25 \%$, and $<25 \%$. (E) Three months after ${ }^{125}$ seed implantation, the tumor became smaller, and the ${ }^{125}$ seeds gathered.

Abbreviations: CT, computed tomography; OAR, organ-at-risk; ${ }^{125}$, iodine-125; TPS, treatment planning system.

the proportion of patients that can be considered candidates for radical surgery (en bloc spondylectomy). Fifty-one consecutive patients were evaluated. Because of the diffuse vertebral involvement in the metastases, no patients in this sample were considered candidates for radical spondylectomy for the removal of vertebral metastases. ${ }^{22}$

Conventional external beam radiotherapy remains the mainstay treatment modality for spinal metastases. The total dose of radiation with conventional external beam radiotherapy ranges from $25 \mathrm{~Gy}$ to $40 \mathrm{~Gy}$ and is fractionated daily into 8-20 doses. ${ }^{23}$ A broad margin is used in the radiation field, typically one or two vertebral segments above and two segments below the affected level, to compensate for internal vertebral motion. This technique exposes healthy tissue to radiation, including the sensitive spinal cord.

The implantation of radioactive isotopes for the treatment of many carcinomas has been used for the past several decades. Numerous studies have confirmed that the implantation of radioactive ${ }^{125} \mathrm{I}$ seeds is a safe and effective method for the treatment of malignant tumors. ${ }^{125} \mathrm{I}$ seeds have the following advantages over other forms of radiotherapy: 1) ${ }^{125}$ I seeds can kill tumor cells continuously by keeping the cells in the resting state and promoting tumor stem cell apoptosis; 2) seed radiation is characterized by attenuation

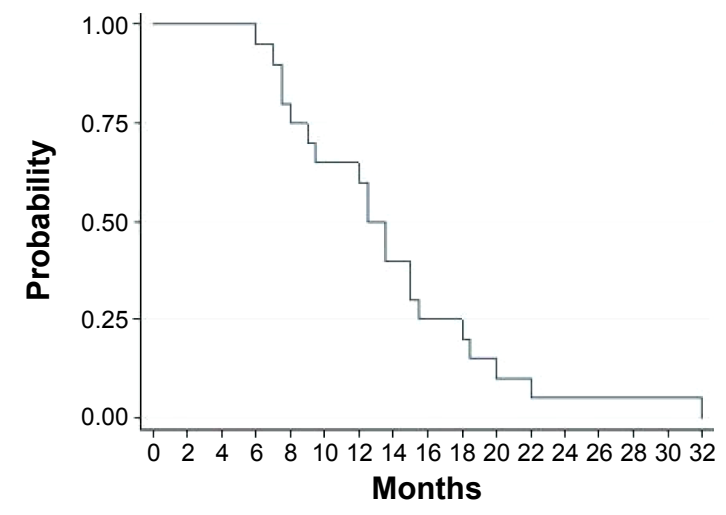

Number at risk

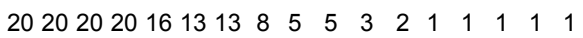

Figure 2 Local control rate after ${ }^{125}$ seed implantation.

Abbreviation: ${ }^{125}$, iodine- 125 . over a short distance, which can maintain a higher accumulative dose (up to $160 \mathrm{~Gy}$ ) within the tumor; 3 ) the internal irradiation is relatively long acting, lasting up to 180 days; 4) the ${ }^{125}$ I seeds can be arranged selectively according to the asymmetrical growth of the tumor; 5) the ${ }^{125}$ I seeds can maximize the local dose and minimize their radiation to the surrounding normal tissues; and 6) the radiation distance of the ${ }^{125} \mathrm{I}$ seeds is only $\sim 1.7 \mathrm{~cm}$, which prevents any potential injury to the sounding tissues. ${ }^{4-6,24-26}$

Yang et al generated a Banna mini-pigs model to mimic percutaneous vertebroplasty with ${ }^{125}$ I seed implantation. ${ }^{27}$ None of the Banna pigs developed radiation myelopathy, and no significant cellular impairment was observed by pathological analysis. Our study showed that the cord doses were $\leq 30 \mathrm{~Gy}$, and the doses for the other OARs, such as the intestine and liver, were $<25 \mathrm{~Gy}$.

The precise implantation of radioactive seeds into the tumors and the reasonable distribution of the seeds based on the volume and density of the tumor and its relationship with the adjacent vital organs achieve directional blasting, maximum destruction of tumor cells, and minimal damage to normal tissue. The ${ }^{125} \mathrm{I}$ seeds could be arranged selectively according to the asymmetrical growth of the tumor. Our study revealed certain key steps of this procedure that require

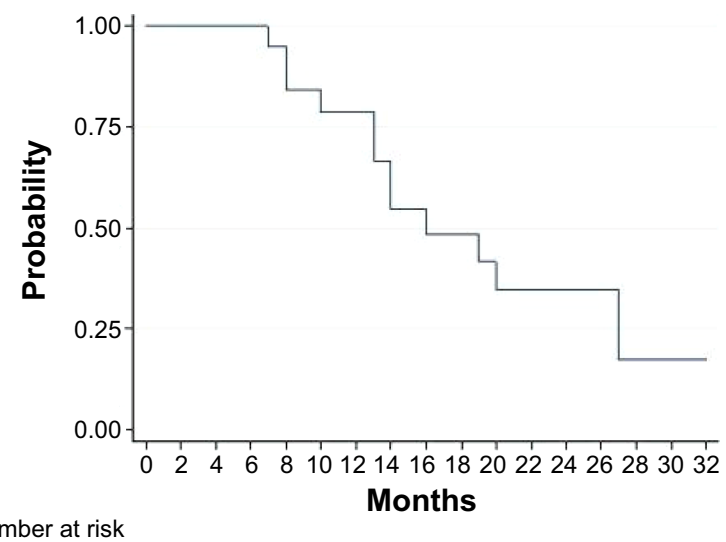

Figure 3 Cumulative survival rate after ${ }^{125}$ seed implantation. Abbreviation: ${ }^{125}$, iodine- 125 . 
particular attention. In the needle deployment plan, the source energy, target size, nearby OARs, and insertion procedures were taken into account. During needle placement, the operator should take care to keep the needles at least $1 \mathrm{~cm}$ away from large blood vessels and the spine. The ${ }^{125} \mathrm{I}$ seeds were implanted at $1.0 \mathrm{~cm}$ intervals. The internal irradiation was relatively long acting, lasting up to 180 days.

Our study had certain limitations. Because of the timelimited study period, the sample size was small; however, our results were statistically significant. Further studies with larger sample sizes may yield more accurate results.

\section{Conclusion}

The implantation of radioactive isotopes for the treatment of spinal metastatic tumors can alleviate pain, preserve or improve neurologic function, achieve mechanical stability, optimize local tumor control, and improve quality of life. This is a potential alternative therapy for the treatment of spinal metastases. Determining the long-term effectiveness of this therapy requires further study.

\section{Acknowledgments}

This work was supported by funds from the Science and Technology Commission of Shanghai Municipality (124119b0800 and 134119b2900) and the Youth Foundation of the Shanghai Public Health Bureau (20124Y062).

\section{Author contributions}

All authors contributed toward data analysis, drafting and critically revising the paper and agree to be accountable for all aspects of the work.

\section{Disclosure}

The authors report no conflicts of interest in this work.

\section{References}

1. Simmons ED, Zheng Y. Vertebral tumors: surgical versus nonsurgical treatment. Clin Orthop Relat Res. 2006;443(2006):233-247.

2. Delank KS, Wendtner C, Eich HT, Eysel P. The treatment of spinal metastases. Dtsch Arztebl Int. 2011;108(5):71-79.

3. Jacobs WB, Perrin RG. Evaluation and treatment of spinal metastases: an overview. Neurosurg Focus. 2001;11(6):1-11.

4. Wang Z, Lu J, Liu L, et al. Clinical application of CT-guided 125I seed interstitial implantation for local recurrent rectal carcinoma. Radiat Oncol. 2011;6(1):138.

5. Zhongmin W, Yu L, Fenju L, Kemin C, Gang H. Clinical efficacy of CTguided iodine-125 seed implantation therapy in patients with advanced pancreatic cancer. Eur Radiol. 2010;20(7):1786-1791.

6. Wang Z, Lu J, Liu T, Chen K, Huang G, Liu F. CT-guided interstitial brachytherapy of inoperable non-small cell lung cancer. Lung Cancer. 2011;74(2):253-257.
7. Martínez-Monge R, Pagola M, Vivas I, López-Picazo JM. CTguided permanent brachytherapy for patients with medically inoperable early-stage non-small cell lung cancer (NSCLC). Lung Cancer. 2008;61(2):209-213.

8. Anglesio S, Calamia E, Fiandra C, et al. Prostate brachytherapy with iodine125 seeds: radiation protection issues. Tumori. 2005;91(4):335-338.

9. Xue J, Waterman F, Handler J, Gressen E. Localization of linked 125I seeds in postimplant TRUS images for prostate brachytherapy dosimetry. Int J Radiat Oncol Biol Phys. 2005;62(3):912-919.

10. Wang Z, Lu J, Gong J, et al. CT-guided radioactive 125 I seed implantation therapy of symptomatic retroperitoneal lymph node metastases. Cardiovasc Intervent Radiol. 2014;37(1):125-131.

11. Chen HH, Jia RF, Yu L, Zhao MJ, Shao CL, Cheng WY. Bystander effects induced by continuous low-dose-rate $125 \mathrm{I}$ seeds potentiate the killing action of irradiation on human lung cancer cells in vitro. Int $J$ Radiat Oncol Biol Phys. 2008;72(5):1560-1566.

12. Cengiz M, Gürdalli S, Selek U, et al. Effect of bladder distension on dose distribution of intracavitary brachytherapy for cervical cancer: three-dimensional computed tomography plan evaluation. Int J Radiat Oncol Biol Phys. 2008;70(2):464-468.

13. Monk BJ, Tewari KS, Puthawala AA, Syed AMN, Haugen JA, Burger RA. Treatment of recurrent gynecologic malignancies with iodine-125 permanent interstitial irradiation. Int J Radiat Oncol Biol Phys. 2002;52(3):806-815.

14. Miller AB, Hoogstraten B, Staquet M, Winkler A. Reporting results of cancer treatment. Cancer. 1981;47(1):207-214.

15. Shiue K, Sahgal A, Chow E, et al. Management of metastatic spinal cord compression. Expert Rev Anticancer Ther. 2010;10(5):697-708.

16. Kilbride L, Cox M, Kennedy CM, Lee SH, Grant R. Metastatic spinal cord compression: a review of practice and care. J Clin Nurs. 2010; 19(13-14):1767-1783.

17. Sciubba DM, Petteys RJ, Dekutoski MB, et al. Diagnosis and management of metastatic spine disease. J Neurosurg Spine. 2010;13(1):94-108.

18. Paholpak P, Sirichativapee W, Wisanuyotin T. Prevalence of known and unknown primary tumor sites in spinal metastasis patients. Open Orthop J. 2012;6(1):440-444.

19. Weigel B, Maghsudi M, Neumann C, Kretschmer R, Müller FJ, Nerlich M. Surgical management of symptomatic spinal metastases. Post-operative outcome and quality of life. Spine (Phila Pa 1976). 1999; 24(21):2240-2246.

20. Wise JJ, Fischgrund JS, Herkowitz HN, Montgomery D, Kurz LT Complication, survival rates, and risk factors of surgery for metastatic disease of the spine. Spine (Phila Pa 1976). 1999;24(18):1943-1951.

21. Ghogawala Z, Mansfield FL, Borges LF. Spinal radiation before surgical decompression adversely affects outcomes of surgery for symptomatic metastatic spinal cord compression. Spine (Phila Pa 1976). 2001; 26(7):818-824.

22. Botelho RV, de Oliveira MF, Rotta JM. Quantification of vertebral involvement in metastatic spinal disease. Open Orthop J. 2013;7(1): 286-291.

23. Finn MA, Vrionis FD, Schmidt MH. Spinal radiosurgery for metastatic disease of the spine. Cancer Contr. 2007;14(4):405-411.

24. Jian L, Zhongmin W, Kemin C, Yunfeng Z, Gang H. MicroPET-CT evaluation of interstitial brachytherapy in pancreatic carcinoma xenografts. Acta Radiol. 2013;54(7):800-804.

25. Wang Z, Lu J, Zhang LY. Biological effects of low-dose-rate irradiation of pancreatic carcinoma cells in vitro using 125I seeds. World J Gastroenterol. 2015;21(8):2336-2342.

26. Wang JJ, Yuan HS, Li JN, Jiang YL, Tian SQ, Yang RJ. CT-guided radioactive seed implantation for recurrent rectal carcinoma after multiple therapy. Med Oncol. 2010;27(2):421-429.

27. Yang Z, Zhang Y, Xu D, et al. Percutaneous vertebroplasty combined with interstitial implantation of $125 \mathrm{I}$ seeds in banna mini-pigs. World J Surg Oncol. 2013;11(2013):46. 


\section{Publish your work in this journal}

OncoTargets and Therapy is an international, peer-reviewed, open access journal focusing on the pathological basis of all cancers, potential targets for therapy and treatment protocols employed to improve the management of cancer patients. The journal also focuses on the impact of management programs and new therapeutic agents and protocols on patient perspectives such as quality of life, adherence and satisfaction. The manuscript management system is completely online and includes a very quick and fair peer-review system, which is all easy to use. Visit http://www.dovepress.com/testimonials.php to read real quotes from published authors.

Submit your manuscript here: http://www.dovepress.com/oncotargets-and-therapy-journal 